\title{
Prediction of Preheating Temperatures for S690Q High Strength Steel Using FEM-Simulation for High Power Laser Welding
}

\author{
Knut Partes ${ }^{1} \cdot$ Malte Schmidt $^{1} \cdot$ Sven Gorny ${ }^{1}$ \\ Accepted: 10 February 2020 / Published online: 28 February 2020 \\ (C) The Author(s) 2020
}

\begin{abstract}
This study investigates a method for predicting the effect of preheating temperatures on the resulting hardness for high power laser welding of high strength steel. An FEM model is introduced containing a hardness calculation based on an existing model. Moreover, the hardness values of experimental results have been measured in order to show the performance of the model. The hardness calculation requires the chemical composition and the t8/5-time at the point of measurement. It is claimed that a calibration of the melt pool width and depth at room temperature only is enough to get reasonable results from the FEM-model for higher preheating temperatures. From the experimental result of a single experiment the width of a weld seam and the depth was deducted. In this study experiments have been done at various preheating temperatures in order to show the correlation between the model and the experimental results at various temperatures. The hardness equation provides suitable results in the verification with the measurements. The prediction of preheating temperature can be done with the resulting t8/5-time of the FEM-model. This method can decrease the amount of time and costs within a production according to testing and analyzing a matrix of process parameters. Moreover it is concluded that this methodology might be used for single item production.
\end{abstract}

Keywords Preheating $\cdot$ High strength steel $\cdot$ Deep penetration laser welding $\cdot$ Predicting hardness $\cdot$ FEM-welding simulation

Knut Partes

knut.partes@jade-hs.de

1 Jade Hochschule, Friedrich-Paffrath-Straße 101, 26389 Wilhelmshaven, Germany 


\section{Introduction}

The use of high-strength steel (HSS) gets more important today. With the increasing mechanical properties, the quantity of material and the weight of constructional parts can decrease [1]. Due to the reduction of the overall weight, economic and environmental advantages arise in industries like e.g. the automotive industry. In industrial production process chains the takt time determines the amount of time available for specific welding tasks. Increasing productivity and decreasing takt times result in the demand of higher process speed. More often laser deep penetration welding processes are used in industrial applications in order to achieve elevated processing velocities. In addition, it is possible to generate deep welding joints with single passes in comparable small production times $[2,3]$.

However, the laser welding process comes with a high-power density inside the laser spot and comparably small diameters. From this follows a strong temperature gradient with rapid cooling speeds inside the heat affected zone (HAZ). Martensitic phase transformation in the weld seam and the HAZ can be the consequence depending on the material. The original micro structure inside the material will be lost in this region. Moreover, welding distortion and residual stresses are largely affected by phase transformation in the cooling process [4]. The amount of martensite and size of the $\mathrm{HAZ}$ are a function of the temperature field and cooling rates respectively. In general the type of welding process and the welding parameters can indirectly control the temperature field and cooling rates. Moreover, the temperature distribution is following the geometry of the joined parts itself. Hence, the unwanted effects are a function of the process conditions. For instance cracks can occur at different process parameters [5] and the formation of pores can be reduced by the process parameters as well [6].

The hardness in laser beam welded high strength steel can be comparably high. Often a post treatment of weld seams is necessary to restore the mechanical properties of the material. This increases the production time and cost of laser beam welded constructions [7]. However, the hardness can be controlled by adapted temperature fields.

Some strategies like preheating can help to reduce the cooling speeds and hence decrease the drawbacks of laser deep penetration welding [8]. An investigation showed that the effect of increasing hardness at the welding seam and HAZ can be reduced by preheating. Correlations between hardness and preheating temperature have been reported in several studies by empirical analysis of measurements and process parameters $[9,10]$. Nevertheless, finding the right preheating temperature can be a cost intensive experiment. In that method the estimation of hardness of weld seam as a function of the preheating temperature is reported. It was possible to conduct an empirical equation for the calculation of the hardness. However, experiments at different preheating temperatures had to be done.

Another investigation shows the prediction of hardness using a neural network model [11]. However, the amount of requested data is high and the portability to transfer this method to other materials is doubtful. Even though the model is not suitable for the preheating temperature prediction. An investigation showed a method to calculate the hardness in the HAZ with the chemical composition and the cooling time between $800{ }^{\circ} \mathrm{C}$ and $500{ }^{\circ} \mathrm{C}$ (t8/5-time) [12]. Measuring the temperature within the weld seam and HAZ in practical conditions is often not possible. Even though the 
measurements would be affected by the measurement method itself. Therefore, the prediction method is less useful for practical tasks.

Using the finite element method (FEM) can provide a realistic temperature field within three dimensional parts. The increase of requested values also increases the calculation time. Even though the results are heavily affected by the quality of the requested process parameters. Using default setting for complex geometries or process parameters can provide insufficient results. Welding simulations can be subdivided into three parts [13]. A Process simulation can provide weld pool profile and dynamics according to process parameters. The heat source is defined by the interaction of laser beam profile and material parameters [14]. Structure and material simulations can provide insights into residual stresses and distortions within three-dimensional part. The heat source is parametrized previously and remains static during the simulation $[15,16]$.

The target of the following investigation is to create a thermos-mechanical calculation model that provides preheating temperatures according to a defined hardness in the weld seam. Therefore an empirical hardness calculation and a FEM model are used. The model is to be validated by experiments. The resulting methodology can be used in any industry working with high strength steel in order to calculate the correct preheating temperature, e.g. the crane industry.

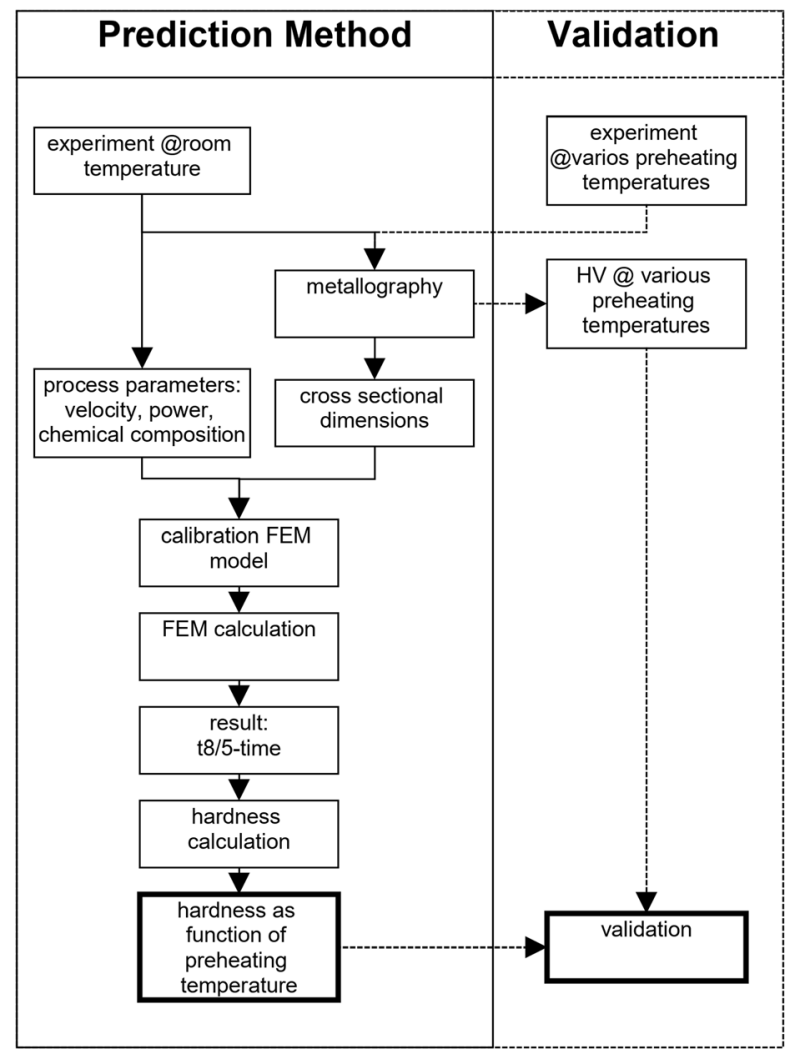

Fig. 1 Method and validation flow chart for the prediction of preheating temperatures 
Table 1 Chemical composion of S690QL by EDXA with acceleration voltage of $20 \mathrm{kV}$

\begin{tabular}{llllllllll}
\hline Chemical components & $\mathrm{C}$ & $\mathrm{Mn}$ & $\mathrm{Si}$ & $\mathrm{Cr}$ & $\mathrm{Ni}$ & $\mathrm{Mo}$ & $\mathrm{V}$ & $\mathrm{Cu}$ & $\mathrm{Nb}$ \\
\hline Base material (BM) Portion [\%] & 0.16 & 0.61 & 0.18 & 0.24 & 0 & 0.25 & 0 & 0 & 0 \\
Weld seam (WS) Portion [\%] & 0.16 & 0.56 & 0.15 & 0.28 & 0 & 0.28 & 0 & 0 & 0 \\
Absolute error [\%] & 0.04 & 0.04 & 0.03 & 0.03 & 0.03 & 0.03 & 0.03 & 0.03 & 0.03 \\
\hline
\end{tabular}

\section{Methodology}

\section{Methodology of Validation}

The basic idea is to use modern FEM-simulation tools for the prediction of properties as a function of preheating temperatures. In practice the validation of the temperature field in the process can be an exhausting process. Hence, in this study it is claimed that a calibration of the melt pool width and depth at room temperature only is enough in order to get reasonable results from the model determining the properties at higher preheating temperatures. From the experimental result of a single experiment the width of a weld seam and the depth was deducted. This was used to model the heat source in the FEM calculation. The methodology of this study is divided into two parts. First the actual method for the prediction of preheat temperatures is made. The second part of the investigation is the validation of the method. Therefore, the results of the method's calculation are compared with the experimental measurements. This validation is not part of the actual prediction method and has only been done in order to show the performance of the model.

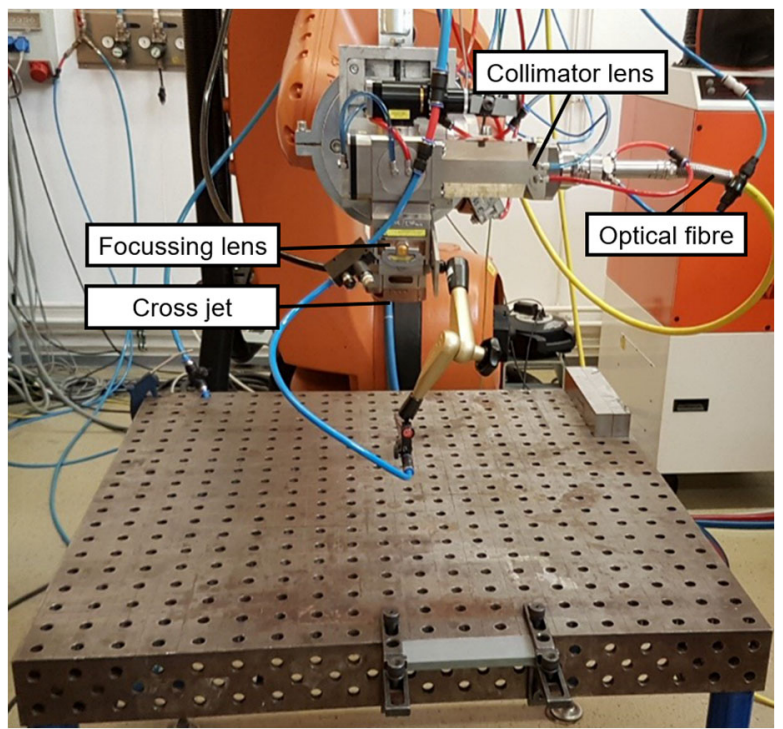

Fig. 2 Experimental setup: $10 \mathrm{~kW}$ fiber laser IPG YLS-10000 with $160 \mathrm{~mm}$ collimator lens, $300 \mathrm{~mm}$ surface lens 
For the prediction method a welding sample at room temperature $\left(20^{\circ} \mathrm{C}\right)$ is made. A metallographic analysis provides the cross-sectional dimensions. Therefore, the depth and wide at the top and bottom of the weld seam are measured. The heat source within the FEM model is calibrated according to this measurement. Furthermore the welding velocity and laser power are integrated into the model. The FEM calculation is done for various preheating temperatures. The resulting $\mathrm{t} 8 / 5$ times for defined elements within the weld seam are exported to the hardness calculation model. Also the chemical composition for the welding sample is provided by an energy dispersive X-ray analysis. The hardness can be calculated according to a specific preheating temperature.

For the validation of the prediction method welding samples are made at various preheating temperatures. The hardness is measured in the weld seam. These measurements are compared with the calculated values for specific preheating temperatures.

The following flow chart describes the method of preheating temperature prediction and the validation of the method itself. See Fig. 1.

\section{Material}

Metal sheets made of S690QL were used for the experiments. The metal sheet thickness is $6 \mathrm{~mm}$. The plates have a length of $200 \mathrm{~mm}$ and a width of $50 \mathrm{~mm}$. The chemical composition has been generated for the base material and the weld seam by an energy dispersive X-ray analysis (EDXA). This analysis was made with an acceleration voltage of $20 \mathrm{kV}$. The results are shown in Table 1 . Due to the insufficient detectability of carbon the value was set to $0.16 \mathrm{wt} \%$ according to [17]. This relates to the material composition in the FEM-model. The absolute error was set to $+-0.04 \mathrm{wt} \%$. The differences between the chemical composition of the base material and the weld seam are neglectable. According to this the following calculations are based on the chemical composition of the base material.

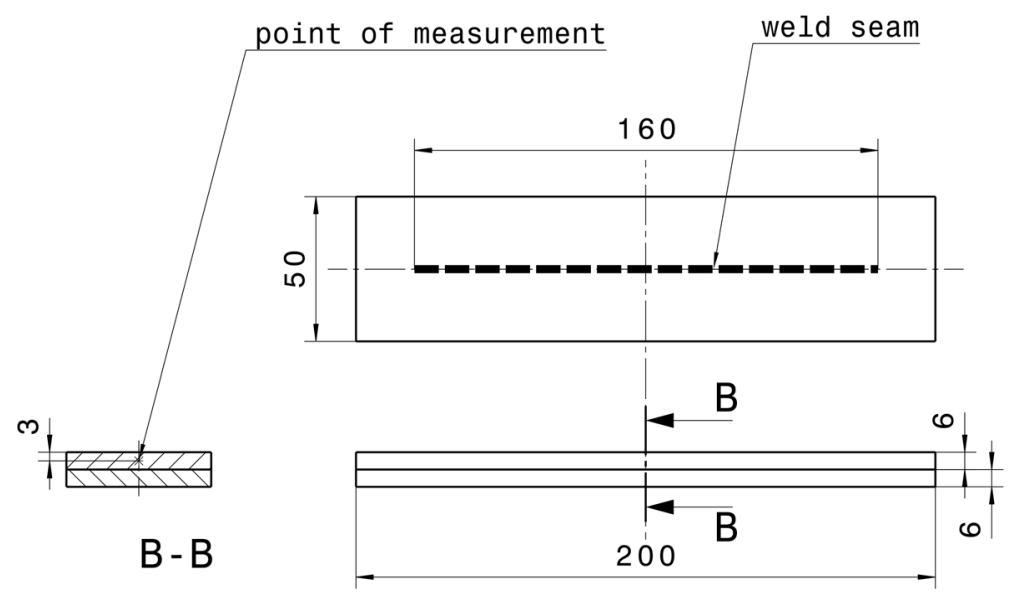

Fig. 3 Welding construction setup 


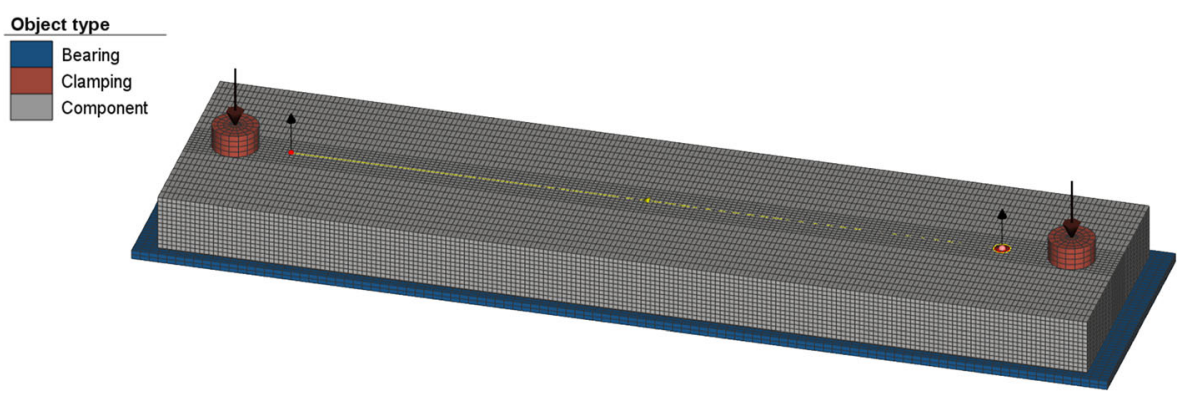

Fig. 4 Meshed FEM volume model containing 339,936 hexahedral elements

\section{Experimental Procedure}

The two plates were clamped in the lap joined configuration. The length of the weld seam is $150 \mathrm{~mm}$ and $25 \mathrm{~mm}$ from each side. The laser source is an IPG YLS-10000. This laser is a fiber laser with a maximum output power of $10 \mathrm{~kW}$. The fiber diameter is $200 \mu \mathrm{m}$. A collimator lens of $160 \mathrm{~mm}$ and focusing lens of $300 \mathrm{~mm}$ were used. The focus was set $4 \mathrm{~mm}$ below the surface of the upper metal sheet. The used laser power was $6 \mathrm{~kW}$ and a travel speed of $1 \mathrm{~m} / \mathrm{min}$. The experimental setup can be seen in Fig. 2.

To investigate the accuracy of the validation the results of the model were compared to the measurements of the experimental welds. An accordance of the validated and measured values is the proof for the model.

For this the welding experiments have been performed with and without preheating. For the preheating the specimen where put into an oven. After the heating process the specimens have been placed into the welding setup. The temperature was measured with a tactile thermometer. The welding process was performed after the plates reached the desired temperature. Experiments have been made at room temperature and at $100{ }^{\circ} \mathrm{C}, 150{ }^{\circ} \mathrm{C}$ and $200{ }^{\circ} \mathrm{C}$ respectively.

The specimens have been investigated by metallographic inspection. Hardness measurements were made in the weld seams at $3 \mathrm{~mm}$ below the surface. The Vickers hardness was measured with a $10 \mathrm{~kg}$ load.

\section{FEM-Model}

The FEM welding model has been set up with a software named Simufact welding. The model is shown in Fig. 4. It has already been reported about Simufact in industrial applications, [18]. The temperature dependent thermophysical and mechanical properties of matter have been provided by the software $[17,19,20]$. The mesh geometry of

Table 2 FEM-model welding process parameters

\begin{tabular}{lc}
\hline Welding Process parameter & Value \\
\hline Velocity & $1 \mathrm{~m} / \mathrm{min}$ \\
Power value & $6000 \mathrm{~W}$ \\
Efficiency & 0.9 \\
\hline
\end{tabular}


Table 3 Configuration of heat source in FEM-model with measured width and depth

\begin{tabular}{|l|l|r|}
\hline \multirow{2}{*}{$d$} & \multicolumn{1}{|c|}{ Heat source parameter } & \multicolumn{1}{c|}{ Value } \\
\cline { 3 - 4 } & Conical heat source upper radius $r_{u}$ & $1.8 \mathrm{~mm}$ \\
\cline { 3 - 4 } & Conical heat source lower radius $r_{l}$ & $0.8 \mathrm{~mm}$ \\
\cline { 3 - 4 } & Conical heat source depth $d$ & $10 \mathrm{~mm}$ \\
\cline { 3 - 4 } & Gaussian parameter $M$ & 3.0 \\
\cline { 3 - 4 } & Volume heat fraction & 1.0 \\
\hline
\end{tabular}

the model has been designed with the software Abaqus FEA. The mesh contains 339,936 hexahedral elements within the volume model. Moreover the mesh has been refined in the direction of the weld seam. In Figs. 3 and 4 the welding construction setup is shown.

The geometry of the heat source was adapted by the laser beam parameters and the cross-sectional area. Width and depth of the weld pool have been taken from the experiment without preheating. Also the process parameters of the experiment are taken into account. See Table 2. The configuration of the heat source is calibrated with the measured depth and width of the weld seam cross section for room temperature. See Table 3. The efficiency was set to a typical value of overall absorption for deep penetration welding processes [21].

\section{Hardness Calculation}

The model describes the calculation of maximum hardness in HAZ for weld seams. Adapting this method is used for hardness calculations in weld seams. According to this method the hardness is connected to the $t 8 / 5$ time by means of the arctangent function. It is necessary to calculate the maximum hardness and t8/5-time of a full martensitic

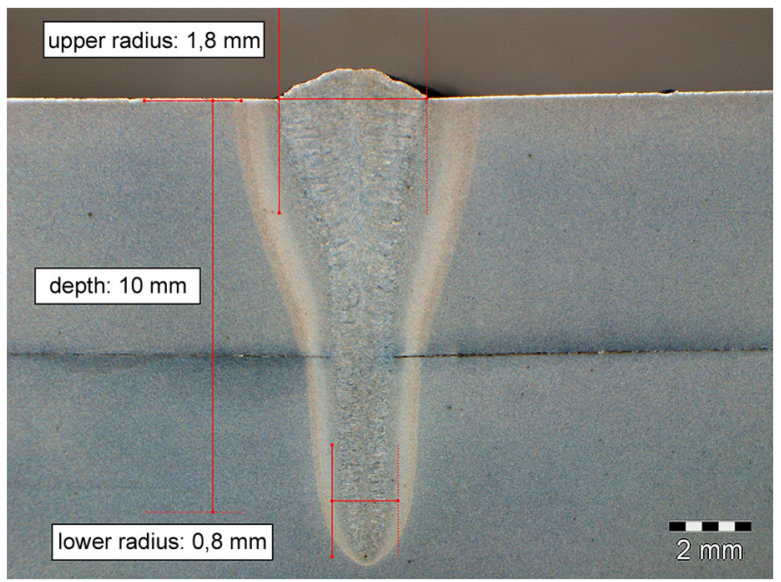

Fig. 5 Laser weld seam with measured width and depth 
Table 4 Hardness measurement at various preheating temperatures

\begin{tabular}{ll}
\hline Preheating temperature $\left[{ }^{\circ} \mathrm{C}\right]$ & Hardness [HV10] \\
\hline 20 & 407 \\
100 & 370 \\
150 & 350 \\
200 & 325 \\
\hline
\end{tabular}

and full bainitic structure. These are based on specific carbon equivalents. The final equation is described as followed, Eqs. 1 and 2. Specific calculations according to [12].

$$
\begin{gathered}
H_{V}=\frac{\left(H_{M}+H_{B}\right)}{2}-\frac{\left(H_{M}+H_{B}\right) * \arctan (X)}{2.2} \\
X=\frac{4 * \log \left(\frac{\tau}{\tau_{M}}\right)}{\log \left(\frac{\tau_{B}}{\tau_{M}}\right)-2}
\end{gathered}
$$

With this equation it is possible to calculate the maximum hardness of a specific $t 8 / 5$ time. These are given by the FEM simulation in this study.

\section{Results}

\section{Metallographic Analysis}

All weld seams show a sound bonding without any kind of defects like cracks or pores in the metallographic cross sectional investigation. The width of the weld seam at the surface is $3.6 \mathrm{~mm}, 1.6 \mathrm{~mm}$ at the bottom and the depth is $10 \mathrm{~mm}$. In Fig. 5 an exemplary cross section without preheating can be seen. The measured width and depth are used for the calibration of the FEM-simulation. However the depth can be calculated by

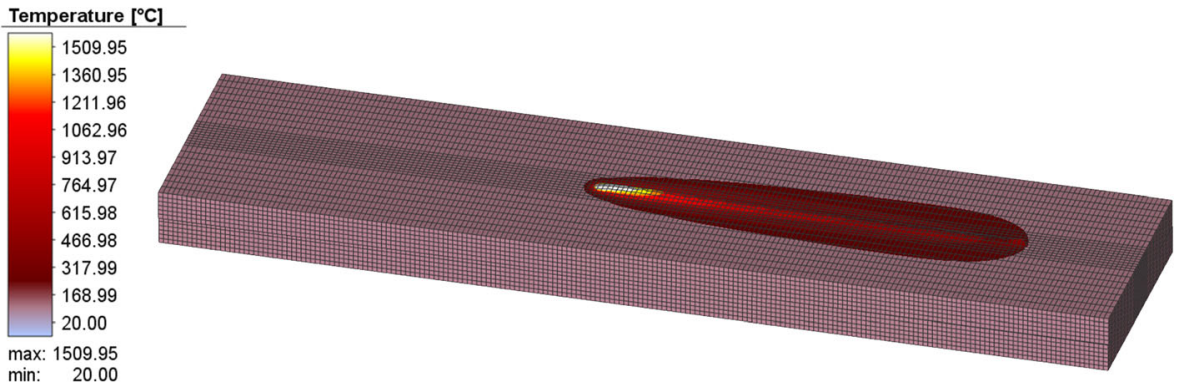

Fig. 6 FEM-model of the temperature field 


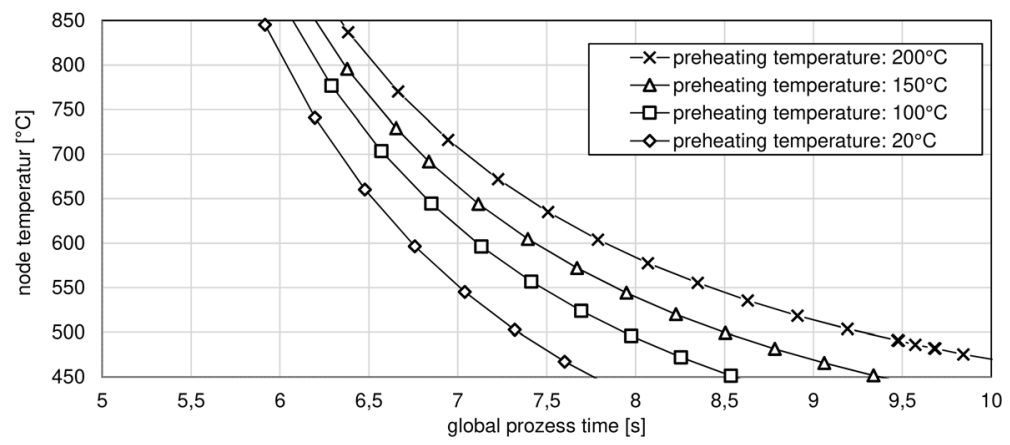

Fig. 7 FEM-model results for different preheating temperatures

analytical approaches [22] but it was decided to go for a practical solution and measure it in order to be able to transfer the model to more complex geometries. See Table 3. The geometry of the weld seam geometry and the calculated seam geometry show a sound accordance. The microstructure shows a martensitic structure in the weld seam.

\section{Hardness Measurement}

The Vickers hardness of all specimen haven been measured with a $10 \mathrm{~kg}$ load. The results are shown in Table 4. The relative error was set to $1.0 \%$ of measured value. The maximum measured Vickers hardness occurs at the weld seam without preheating with 407 HV10. The higher the preheating temperature the lower the hardness in the weld seam. At a preheating temperature of $200{ }^{\circ} \mathrm{C}$ the measured Vickers hardness drops down to $325 \mathrm{HV} 10$. The initial measured Vickers hardness of the specimen is $285 \mathrm{HV} 10$.

\section{FEM-Simulations-Results}

The requested t $8 / 5$ time is provided by the temperature of specific nodes in the simulation. In Fig. 6 the result from the FEM simulation without preheating is shown. Each node of the FEM-model contains a separate temperature for each time step. The following data contains to the node in the middle of the weld seam at $3 \mathrm{~mm}$ below the surface. The results for each preheating simulation are shown in Fig. 7.

According to the temperature-time dataset the $t 8 / 5$ times have been calculated. The accurate times of $800{ }^{\circ} \mathrm{C}$ and $500{ }^{\circ} \mathrm{C}$ are calculated with linear interpolation. With the increase of preheating temperature, the $t 8 / 5$ times also increase. Due to the chosen time increments the total error for the $t 8 / 5$-time is set to $0.2 \mathrm{~s}$. See Table 5 .

Table 5 Calculated t8/5 times based on FEM-model results for various preheating temperatures

\begin{tabular}{lc} 
Preheating temperature $\left[{ }^{\circ} \mathrm{C}\right]$ & t8/5-time $[\mathrm{s}]$ \\
\hline 20 & 1.3 \\
100 & 1.7 \\
150 & 2.1 \\
200 & 2.7 \\
\hline
\end{tabular}


Table 6 Calculated hardness of laser weld seams based on FEM-model results for various preheating temperatures and hardness calculation model

\begin{tabular}{llll}
\hline $\begin{array}{l}\text { Preheating temperature } \\
{\left[{ }^{\circ} \mathrm{C}\right]}\end{array}$ & $\begin{array}{l}\mathrm{t} 8 / 5 \\
{[\mathrm{~s}]}\end{array}$ & $\begin{array}{l}\text { hardness calculation } \\
{[\mathrm{HV} 10]}\end{array}$ & $\begin{array}{l}\text { Absolute error hardness calculation } \\
{[\mathrm{HV} 10]}\end{array}$ \\
\hline 20 & 1.3 & 396 & 55 \\
100 & 1.7 & 380 & 44 \\
150 & 2.1 & 363 & 37 \\
200 & 2.7 & 342 & 32 \\
\hline
\end{tabular}

\section{Hardness Calculation}

The calculation uses the chemical composition of the base material and the $t 8 / 5$ - time from the FEM model. In Table 6 all calculated values can be seen. The hardness decreases with increasing preheating temperature. The error propagation has been used according to Eq. 3 and [23] in order to calculate the error in the hardness.

$$
\Delta f=\sqrt{\left(\frac{\partial f}{\partial x_{1}}\right)^{2} \cdot \Delta x_{1}^{2}+\left(\frac{\partial f}{\partial x_{2}}\right)^{2} \cdot \Delta x_{2}^{2}+\ldots}
$$

The error of the calculated value $\mathrm{f}$ is given by $\Delta \mathrm{f}$. The different variables and individual errors are given by $\mathrm{x}_{\mathrm{n}}$ and $\Delta \mathrm{x}_{\mathrm{n}}$ respectively. All values have been integrated in this calculation. The calculated hardness at a preheating temperature of $20{ }^{\circ} \mathrm{C}$ is $396 \mathrm{HV} 10$. This is the maximum hardness that has been calculated. With the increasing preheating temperature, the calculated hardness decreases. At $200{ }^{\circ} \mathrm{C}$ preheating temperature the calculated hardness drops down to $342 \mathrm{HV} 10$. This can be seen in Fig. 8 with the arctan function. With the increasing preheating temperature, the absolute error for the hardness calculation decreases.

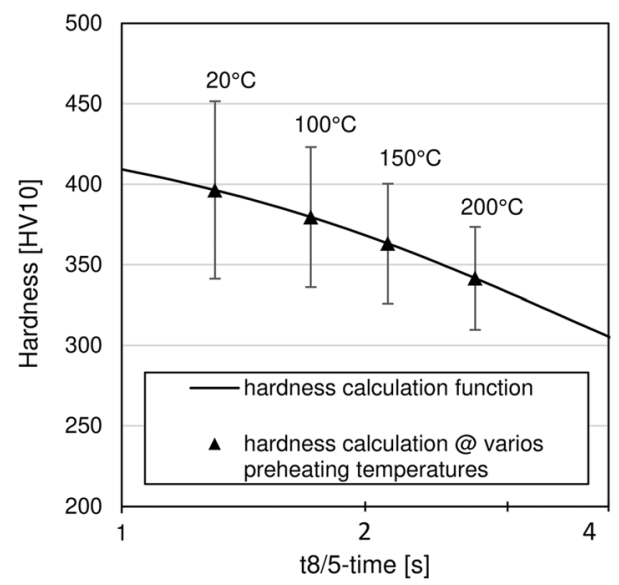

Fig. 8 Hardness calculation arctan-function 


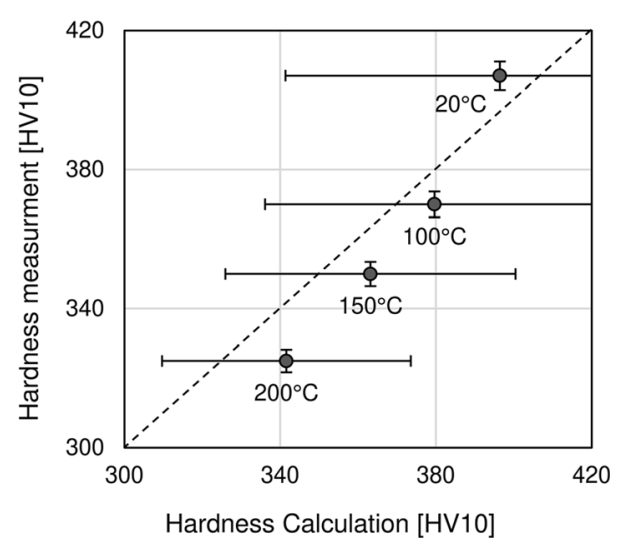

Fig. 9 Comparison of measured and calculated weld seam hardness

\section{Discussion}

In Fig. 9 the calculated and the measured hardness are related to each other. These values are attributed to the associated preheating temperatures. Without preheating at room temperature $\left(20{ }^{\circ} \mathrm{C}\right)$ the calculated hardness $(396 \mathrm{HV} 10)$ underestimates the measured hardness (407 HV10) in the weld seam. The absolute difference amounts to -11 HV10 and the relative difference based on the measured hardness is $2.7 \%$. The calculations for higher preheating temperatures $100{ }^{\circ} \mathrm{C}, 150{ }^{\circ} \mathrm{C}$ and $200{ }^{\circ} \mathrm{C}$ overestimate the measured hardness. For preheating at $100^{\circ} \mathrm{C}$ the absolute difference amounts up to $+10 \mathrm{HV} 10$ and relative up to $2.7 \%$. With the increasing preheating temperature, the difference between calculation and measurement also increases. At $200{ }^{\circ} \mathrm{C}\left(150^{\circ} \mathrm{C}\right)$ preheating the absolute difference is up to $17 \mathrm{HV} 10$ (13 HV10) and relative at 5.2\% (3.7\%). The calculated absolute error area of the calculated hardness covers the measured hardness for all preheating temperatures.

In future work the application of this model on other steels could be investigated. It might be limited by the application of the yurioka model for hardness only. Moreover,

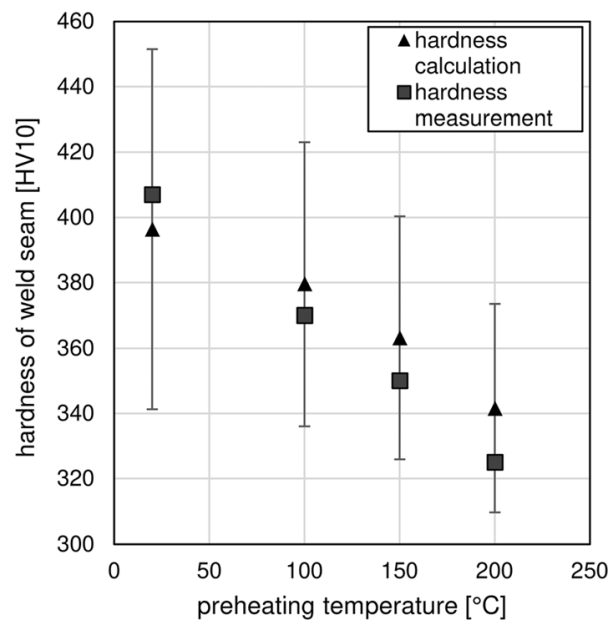

Fig. 10 Comparison of calculated and measured hardness as function of the preheating temperature 
modelling the effect of post processing heat treatment on the microstructure and properties could be interesting aspects to investigate.

\section{Conclusion}

In this investigation the potential of welding simulation has been shown. The combination of validating the FEM-model with measurements and the use of calculationmodels can provide solid results. In Fig. 10 the calculated and the measured hardness are compared related to the preheating temperature. With this method it is possible to predict preheating temperatures for specific materials. Modern-day computers and userfriendly simulation software make similar calculations possible in reasonable times. The prediction of the proper preheating temperature can be realized with comparably low effort. Moreover, the experimental validation can be done via microstructural investigations of the weld seam geometry and a hardness test. No further analysis is necessary. The essential results of this study are the following:

- Preheating can decrease the maximum hardness within the weld seam of S690 high strength steel for high power laser welding

- The error of the chemical composition measurement has a major effect on the calculated hardness. An accurate measurement is required to provide suitable results for the hardness calculation

- The calibration of FEM-model with experimental dimension is needed to provide realistic results

Acknowledgements IPG Laser GmbH - The experiments were done in the application lab of IPG laser. Thanks to Michael Grupp from IPG laser for making the experiments with us.

Thanks to the laboratory of Materials Science and physics at the Jade Hochschule. Alexander Rigos and Helmut Schütte supported us with metallographic analysis and EDX inspection.

Thanks to Pavel Khazan from Simufact Welding for the fruitful discussions.

Thanks the Manitowoc Crane Group Germany GmbH supporting our work with materials.

Funding Information Open Access funding provided by Projekt DEAL.

Open Access This article is licensed under a Creative Commons Attribution 4.0 International License, which permits use, sharing, adaptation, distribution and reproduction in any medium or format, as long as you give appropriate credit to the original author(s) and the source, provide a link to the Creative Commons licence, and indicate if changes were made. The images or other third party material in this article are included in the article's Creative Commons licence, unless indicated otherwise in a credit line to the material. If material is not included in the article's Creative Commons licence and your intended use is not permitted by statutory regulation or exceeds the permitted use, you will need to obtain permission directly from the copyright holder. To view a copy of this licence, visit http://creativecommons.org/licenses/by/4.0/.

\section{References}

1. Günther, H.-P., Hildebrand, J., Rasche, C., Christian, V., Wudtke, I., Kuhlmann, U., Vormwald, M., Werner, F.: Welded connections of high-strength steels for the building industry. Weld World. 56(5-6), 86-106 (2012). https://doi.org/10.1007/BF03321353 
2. Poprawe, R.: Lasertechnik für die Fertigung. Grundlagen, Perspektiven und Beispiele für den innovativen Ingenieur ; mit 26 Tabellen. VDI-Buch. Springer-Verlag Berlin Heidelberg, Berlin, Heidelberg (2005)

3. Quintino, L., Costa, A., Miranda, R., Yapp, D., Kumar, V., Kong, C.J.: Welding with high power fiber lasers - a preliminary study. Mater. Des. (2007). https://doi.org/10.1016/j.matdes.2006.01.009

4. Kim, Y.-C., Hirohata, M., Inse, K.: Effects of phase transformation on distortion and residual stress generated by laser beam welding on high-strength steel. Weld World. 56(3-4), 64-70 (2012). https://doi. org/10.1007/BF03321336

5. Liu, D., Li, Y., Liu, H., et al.: Numerical investigations on residual stress in laser penetration welding process of ultrafine-grained steel. Adv. Mater. Sci. Eng. 3, 1-12 (2018). https://doi.org/10.1155/2018 /8609325

6. Tucker, J.D., Nolan, T.K., Martin, A.J., Young, G.A.: Effect of travel speed and beam focus on porosity in alloy 690 laser welds. JOM. 64(12), 1409-1417 (2012). https://doi.org/10.1007/s11837-012-0481-3

7. Suominen, L., Khurshid, M., Parantainen, J.: Residual stresses in welded components following postweld treatment methods. Procedia Eng. (2013). https://doi.org/10.1016/j.proeng.2013.12.073

8. Xin, D., Cai, Y., Hua, X.: Effect of preheating on microstructure and low-temperature toughness for coarse-grained heat-affected zone of 5\% Ni steel joint made by laser welding. Weld World. 63(5), 12291241 (2019). https://doi.org/10.1007/s40194-019-00739-8

9. Piekarska, W., Goszczyńska-Króliszewska, D., Domański, T., Bokota, A.: Analytical and numerical model of laser welding phenomena with the initial preheating. Procedia Eng. (2017). https://doi. org/10.1016/j.proeng.2017.02.206

10. Lahdo, R., Seffer, O., Springer, A., Kaierle, S., Overmeyer, L.: GMA-laser hybrid welding of highstrength fine-grain structural steel with an inductive preheating. Phys. Procedia. (2014). https://doi. org/10.1016/j.phpro.2014.08.060

11. Trzaska, J.: Neural networks model for prediction of the hardness of steels cooled from the austenitizing temperature. Arch. Mater. Sci. Eng. (2016). https://doi.org/10.5604/01.3001.0009.7105

12. Kasuya, T., Yurioka, N., Okumura, M.: Methods for Predicting Maximum Hardness of Heat-Affected Zone and Selecting Necessary Preheat Temperature for Steel Welding. nippon steel technical report(65), 7-14 (1995)

13. Cerjak, H. (ed.): Mathematical modelling of weld phenomena 6. [Sixth International Seminar on the Numerical Analysis of Weldability, held during October 2001, Schloss Seggau near Graz, Austria]. Book / Institute of Materials, Minerals and Mining, vol. 784. Maney, London (2002)

14. Cho, W.-I., Na, S.-J., Thomy, C., Vollertsen, F.: Numerical simulation of molten pool dynamics in high power disk laser welding. J. Mater. Process. Technol. (2012). https://doi.org/10.1016/j. jmatprotec.2011.09.011

15. Deng, D., Kiyoshima, S.: Numerical simulation of welding residual stresses in a multi-pass buttwelded joint of austenitic stainless steel using. acta metallurgica sinica (2010). https://doi.org/10.3724/SP. J.1037.2009.00521

16. Deng, D.: FEM prediction of welding residual stress and distortion in carbon steel considering phase transformation effects. Mater. Des. (2009). https://doi.org/10.1016/j.matdes.2008.04.052

17. Schroeter, F.: Hoeherfeste Staehle fuer den Stahlbau-Auswahl und Anwendung/High-strength steels for steel construction-selection and application. Bauingenieur(9) (2003)

18. Perret, W., Thater, R., Alber, U., et al.: Approach to assess a fast welding simulation in an industrial environment - Application for an automotive welded part. Int. J. Automot. Technol. 12, 895-901 (2011). https://doi.org/10.1007/s12239-011-0102-0

19. Seyffarth, P., Meyer, B., Scharff, A.: Großer Atlas Schweiss-ZTU-Schaubilder. Fachbuchreihe Schweisstechnik, vol. 110. Dt. Verl. für Schweisstechnik DVS-Verl., Düsseldorf (1992)

20. Wink, H.-J., Krätschmer, D.: Charakterisierung und Modellierung des Bruchverhaltens von Punktschweißverbindungen in pressgehärteten Stählen, Teil II - Simulation des Schweißprozesses. 11. LS-DYNA Forum, Ulm, 201217

21. Neumann, Steffen - Einflussanalyse beim single mode Faserlaserschweißen zur Vermeidung des Humping-Phänomens: Strahltechnik Band 48, BIAS Verlag, 2012.; ISBN 978-3-933762-42-9

22. Kim, J.D.: Prediction of the penetration depth in laser beam welding. KSME J. 4(1), 32-39 (1990). https://doi.org/10.1007/BF02953388

23. $\mathrm{Ku}, \mathrm{H}$., Notes on the Use of Propagation of Error Formulas. Journal of research of the National Bureau of Standards - C. Engineering and Instrumentation; Vol. 70C, No.4, October-December 1966

Publisher's Note Springer Nature remains neutral with regard to jurisdictional claims in published maps and institutional affiliations. 